\title{
Hot-wire polysilicon waveguides with low deposition temperature
}

\author{
Taha M. Ben Masaud, ${ }^{1, *}$ Antulio Tarazona, ${ }^{3}$ Ehsan Jaberansary, ${ }^{1}$ Xia Chen, ${ }^{2}$ Graham T. Reed, ${ }^{2}$ \\ Goran Z. Mashanovich, ${ }^{2}$ and H. M. H. Chong ${ }^{1}$ \\ ${ }^{1}$ Electronics and Computer Science, University of Southampton, University Road, Southampton SO17 1BJ, UK \\ ${ }^{2}$ Optoelectronics Research Centre, University of Southampton, University Road, Southampton SO17 1BJ, UK \\ ${ }^{3}$ Echerkon Technologies Ltd., 20 Springfield Road, Crawley RH11 oDN, UK \\ *Corresponding author: tbm206@ecs.soton.ac.uk
}

Received June 3, 2013; revised August 23, 2013; accepted August 30, 2013;

posted September 5, 2013 (Doc. ID 191691); published October 4, 2013

\begin{abstract}
We fabricated and measured the optical loss of polysilicon waveguides deposited using hot-wire chemical vapor deposition at a temperature of $240^{\circ} \mathrm{C}$. A polysilicon film $220 \mathrm{~nm}$ thick was deposited on top of a $2000 \mathrm{~nm}$ thick plasma-enhanced chemical vapor deposition silicon dioxide layer. The crystalline volume fraction of the polysilicon film was measured by Raman spectroscopy to be $91 \%$. The optical propagation losses of 400, 500, and $600 \mathrm{~nm}$ waveguides were measured to be $16.9,15.9$, and $13.5 \mathrm{~dB} / \mathrm{cm}$, respectively, for transverse electric mode at the wavelength of $1550 \mathrm{~nm}$. Scattering loss is expected to be the major contributor to the propagation loss. @ 2013 Optical Society of America

OCIS codes: (130.3120) Integrated optics devices; (130.3130) Integrated optics materials.

http://dx.doi.org/10.1364/OL.38.004030
\end{abstract}

Silicon photonics technology can overcome the limitations of wired interconnections to large scale integration (LSI) circuits by using ultracompact, energy efficient, and high bandwidth silicon circuits [1,2]. Silicon-oninsulator (SOI) has been the dominant development platform for silicon photonics technology due to its low optical propagation loss. However, SOI is limited to lateral integration of photonics and electronics components. Vertical integration of photonic devices is usually performed through direct deposition of amorphous or polycrystalline silicon layers [3-6]. Multilayered integration is desirable due to several advantages such as reduced chip size and improved thermal isolation. Recently, there has been an increased interest in polysilicon waveguides due to their low cost and added design flexibility [3-10]. However, most of the reported polysilicon films were deposited or posttreated at high temperatures $\left(\geq 900^{\circ} \mathrm{C}\right)$, e.g., [3,6-10]. This high temperature may not be suitable for multilayer integration and back-end fabrication processing [11]. Therefore, we propose polysilicon waveguides with low thermal fabrication budget achieved using a hot-wire chemical vapor deposition (HWCVD) method.

An important characteristic of polysilicon waveguides is their low-cost compared to SOI. However, earlier reported optical propagation losses $(35-77 \mathrm{~dB} / \mathrm{cm})$ abated the interest for using polysilicon in photonics applications [5] Engineering the waveguide structure and deposition processes has recently resulted in reducing the optical propagation loss to $\sim 6 \mathrm{~dB} / \mathrm{cm}$ for transverse electric (TE) mode [7]. However, annealing polysilicon at temperatures $\geq 900^{\circ} \mathrm{C}$ has been widely used to improve the crystallinity of as-deposited polysilicon films. Takei et al. reported low-loss, $6.5 \mathrm{~dB} / \mathrm{cm}$, silicon waveguides using hydrogenated microcrystalline silicon $(\mu \mathrm{c}-\mathrm{Si}: \mathrm{H})$ deposited at $250^{\circ} \mathrm{C}$ [11]. However, microcrystalline silicon has inferior electronic properties to polysilicon that may restrict the use of microcrystalline silicon to passive optical devices. In contrast, polysilicon exhibits good electrical and optical properties for silicon photonics technology.
To avoid high deposition temperatures, we used HWCVD instead of the more conventional low pressure chemical vapor deposition and plasma-enhanced chemical vapor deposition (PECVD) processing. In a HWCVD process, the precursor gas (silane) is efficiently broken into radicals using a remote filament while the substrate is only heated at low temperatures [12]. Advantages of HWCVD include low deposition temperatures $\left(\leq 300^{\circ} \mathrm{C}\right)$, low ion-induced damage, high deposition rate, controllable uniformity, large and scalable deposition area, and lower-cost polysilicon films [12].

Thin intrinsic polysilicon films (220 nm thick) were deposited by Echerkon's Nitor 301 HWCVD system at a substrate temperature of $240^{\circ} \mathrm{C}$ with a silane and hydrogen gas mixture. Silane $\left(\mathrm{SiH}_{4}\right)$ decomposition was achieved by $75 \mu \mathrm{m}$ thick tantalum filaments heated at $1850^{\circ} \mathrm{C}$. A $2000 \mathrm{~nm}$ thick PECVD silicon dioxide $\left(\mathrm{SiO}_{2}\right)$ layer was first deposited at $350^{\circ} \mathrm{C}$ prior to polysilicon deposition to form optical isolation. Submicrometer waveguides were then realized using e-beam lithography and conventional reactive-ion etching with fluorinebased chemistry. The waveguides were then covered with a $700 \mathrm{~nm}$ PECVD $\mathrm{SiO}_{2}$ layer that was deposited at a temperature of $350^{\circ} \mathrm{C}$, as shown in Fig. 1 . Atomic force microscopy (AFM) measurement of the surface roughness of the polysilicon films revealed an RMS roughness of $8.9 \mathrm{~nm}$, an autocorrelation length of $100 \mathrm{~nm}$, and an average grain size of $\sim 85 \mathrm{~nm}$ (Fig. 2) .

The crystallinity of the polysilicon layer was analyzed using Raman spectroscopy with a $532 \mathrm{~nm}$ excitation laser. The crystalline volume fraction, $X_{c}$, of the film was calculated using

$$
X_{c}=\frac{I_{c-S i}}{I_{c-S i}+I_{a-S i}},
$$

where $I_{c-S i}$ and $I_{a-S i}$ are the sum of the deconvoluted intensities for the crystalline silicon peaks, centered at 


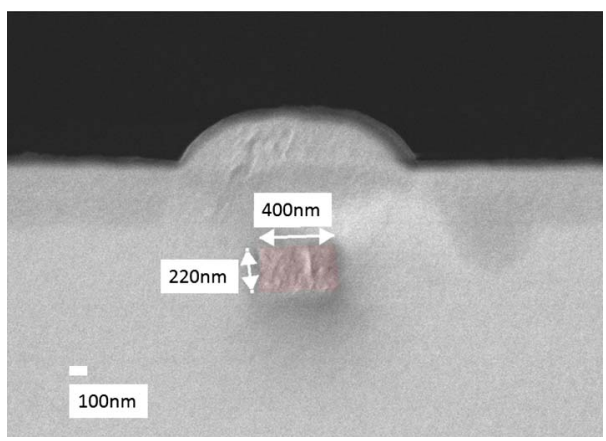

Fig. 1. SEM cross-section of the polysilicon waveguide covered with PECVD $\mathrm{SiO}_{2}$.

520 and $510 \mathrm{~cm}^{-1}$, and the amorphous silicon peak centered at $480 \mathrm{~cm}^{-1}$, respectively [13]. The crystalline volume was found to be $91 \%$, as shown in Fig. 3.

The transmission properties of the single-mode HWCVD polysilicon waveguides were characterized using the cut-back method at a wavelength of $1550 \mathrm{~nm}$. An Agilent Lightwave 81949A C/L band was used as a laser source. The coupling loss of the nanohole grating couplers was estimated to be approximately $10 \mathrm{~dB}$. The design of the nanohole grating couplers allows coupling of TE mode only. The fabricated waveguides had lengths of $0.1,0.25,0.5,0.85$, and $1.3 \mathrm{~cm}$ and widths of 400,500 , and $600 \mathrm{~nm}$. Figure 4 shows that the linear fit of the extracted transmission losses of the TE mode of the 400, 500, and $600 \mathrm{~nm}$ waveguides were found to be $16.9 \pm 0.4,15.9 \pm 0.2$, and $13.5 \pm 0.3 \mathrm{~dB} / \mathrm{cm}$, respectively. It can be seen that the loss reduces for wider waveguides due to reduced interaction of the optical mode with the sidewall and top surface roughness (Fig. 5).

Several loss mechanisms may contribute to the total propagation loss. The absorption loss $L_{\mathrm{Absorp}}$ is minimal because of the hydrogen-terminated dangling bonds. The RMS roughness of the $\mathrm{SiO}_{2}$ PECVD was less than $0.5 \mathrm{~nm}$. Hence, the scattering loss due the bottom polysilicon- $\mathrm{SiO}_{2}$ interface roughness was assumed to be minimal. However, scattering loss from the grain boundaries, sidewall roughness, and top surface roughness can be significant. Scattering loss is generally a function of the confinement factor, $\Gamma$, which is in turn a function of the waveguide width, $\Gamma(w)$, for a given thickness. Hence, the propagation loss can be expressed as

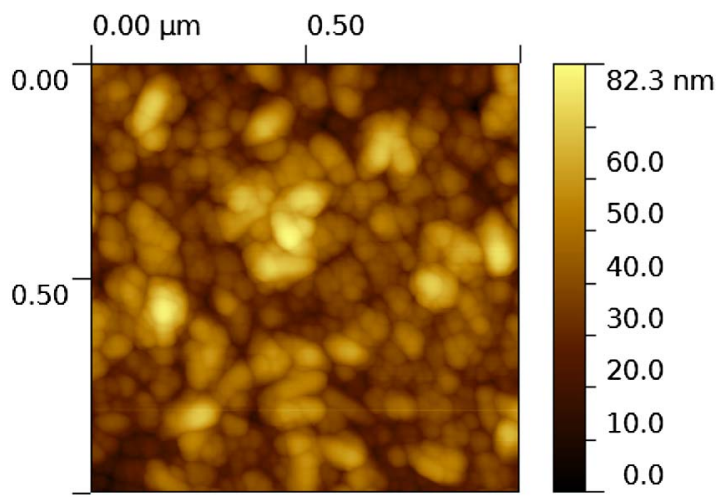

Fig. 2. Topographical AFM image of the polysilicon film deposited at $240^{\circ} \mathrm{C}$ using HWCVD. The RMS surface roughness was measured to be $8.9 \mathrm{~nm}$.

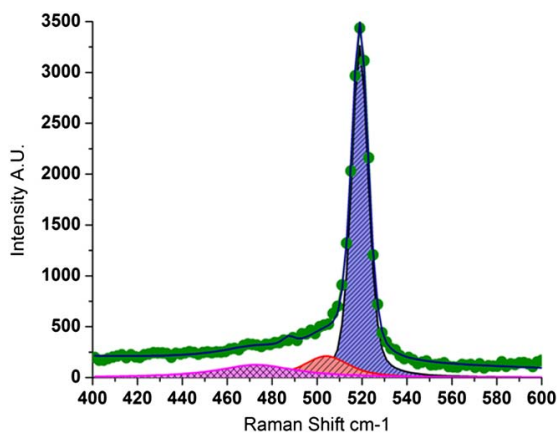

Fig. 3. Raman spectrum of the polysilicon film. Curve-fitting shows a crystalline volume of $91 \%$ (blue-shaded area).

$$
\begin{aligned}
& P_{\text {Loss }} \approx L_{\text {MatScatt }}(\Gamma(w))+L_{\text {TopScatt }}(\Gamma(w)) \\
& \quad+L_{\text {SideScatt }}(\Gamma(w)),
\end{aligned}
$$

where $L_{\text {MatScatt }}, L_{\text {TopScatt }}$, and $L_{\text {SideScatt }}$ are the scattering losses due to grain boundaries, top roughness, and sidewall roughness, respectively.

3D finite-difference time-domain (FDTD) method was used to estimate the loss produced by both the top surface and sidewall roughness. FDTD Solutions by Lumerical Inc. was used to simulate a $220 \mathrm{~nm}$ thick and $500 \mathrm{~nm}$ wide waveguide with propagation lengths of $0.25,0.5$, 0.75 , and $1 \mathrm{~cm}$. The propagation loss was evaluated using the cut-back method. The geometry of the waveguide supports TE mode only and the confinement factor was estimated to be 0.95 . The roughness parameters, extracted from AFM measurements, such as the RMS value and the autocorrelation length, were incorporated into the roughness model. The sidewall roughness of the waveguide had an RMS value of $4 \mathrm{~nm}$ with an autocorrelation length of $120 \mathrm{~nm}$. The material-induced absorption loss was excluded from the model. The simulation mesh had a resolution of $2 \mathrm{~nm}$. Simulation results showed that the loss caused by the top surface and sidewall roughness were 9.2 and $3.1 \mathrm{~dB} / \mathrm{cm}$, respectively.

In order to confirm our simulation estimates, a 2D Fourier method was also used to calculate the loss contributions from the sidewall and the top surface roughness using the same structure and parameters used in the FDTD method [14]. Table 1 summarizes the simulation results of the $3 \overline{\mathrm{D}}$ FDTD and the $2 \mathrm{D}$ Fourier methods.

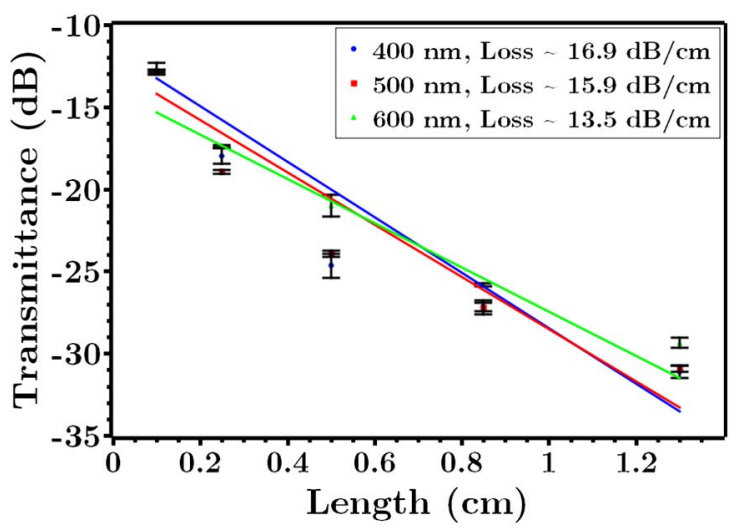

Fig. 4. Transmission characteristics of the TE mode of the polysilicon waveguides of widths 400,500 , and $600 \mathrm{~nm}$. 


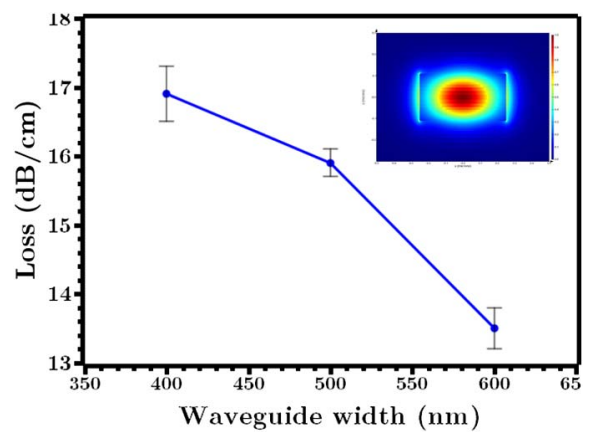

Fig. 5. Transmission loss of the TE mode of the polysilicon waveguides with different widths. The inset shows the confinement of the TE mode in a $500 \mathrm{~nm}$ polysilicon waveguide in FDTD solutions.

The table shows that there is a discrepancy of only $\pm 0.2 \mathrm{~dB} / \mathrm{cm}$ between the two methods. The results from the two simulation methods show that the roughness of top surface has a higher impact on the transmission loss than that of the sidewall.

The material-induced loss can be calculated using the extinction coefficient, $k$. We used a J. A. Woollam spectroscopic ellipsometry system (192-1700 nm) and a multilayer model to calculate the extinction coefficient from which the material-induced loss was found to be approximately $5.1 \mathrm{~dB} / \mathrm{cm}$. Provided the scattering loss is completely eliminated, the material-induced loss is similar to those of previously reported polysilicon waveguides $[7,10]$. The loss can be further reduced by surface planarization by means of chemical mechanical polishing or similar methods. The grain boundaries scattering loss can be improved by deposition at higher temperatures than $240^{\circ} \mathrm{C}$.

In summary, we report on polysilicon waveguides with transmission losses ranging between 13.5 and $16.9 \mathrm{~dB} / \mathrm{cm}$ deposited by HWCVD at $240^{\circ} \mathrm{C}$. Materialinduced loss was found to be $\approx 5.1 \mathrm{~dB} / \mathrm{cm}$. Surface roughness, which was the major loss contributor, can be reduced by engineering the surface topography of the polysilicon films. Future work will focus on improving the crystallinity and surface roughness of the polysilicon films.
Table 1. Contribution of the Scattering Losses Due to the Top Surface and Sidewall Roughnesses

\begin{tabular}{lcc}
\hline & $L_{\text {TopScatt }}(\mathrm{dB} / \mathrm{cm})$ & $L_{\text {SideScatt }}(\mathrm{dB} / \mathrm{cm})$ \\
\hline FDTD & 9.2 & 3.1 \\
2D Fourier & 9.4 & 2.9 \\
\hline
\end{tabular}

The author would like to express his gratitude to the Libyan Ministry of Higher Education and the University of Southampton for their financial and academic support. This work was also funded by the EPSRC in the UK under the UK Silicon Photonics project (EP/F001894/1). G. Z. Mashanovich would like to acknowledge support by the Royal Society through the Royal Society Research Fellowship.

\section{References}

1. S. J. B. Yoo, Electron. Lett. 45, 584 (2009).

2. B. Jalali, S. Fathpour, M. Paniccia, and G. T. Reed, J. Lightwave Technol. 24, 4600 (2006).

3. K. Preston, B. Schmidt, and M. Lipson, Opt. Express 15, 17283 (2007).

4. A. Biberman, K. Preston, G. Hendry, N. Sherwood-Droz, J. Chan, J. S. Levy, M. Lipson, and K. Bergman, ACM J. Emerg. Technol. 7, 1 (2011).

5. J. S. Foresi, M. R. Black, A. M. Agarwal, and L. C. Kimerling, Appl. Phys. Lett. 68, 2052 (1996).

6. L. Liao, D. R. Lim, A. M. Agarwal, X. Duan, K. K. Lee, and L. C. Kimerling, J. Electron. Mater. 29, 1380 (2000).

7. J. S. Orcutt, S. D. Tang, S. Kramer, K. Mehta, H. Li, V. Stojanović, and R. J. Ram, Opt. Express 20, 7243 (2012).

8. S. Zhu, Q. Fang, M. B. Yu, G. Q. Lo, and D. L. Kwong, Opt. Express 17, 20891 (2009).

9. K. Preston, P. Dong, B. Schmidt, and M. Lipson, Appl. Phys. Lett. 92, 151104 (2008).

10. Q. Fang, J. F. Song, S. H. Tao, M. B. Yu, G. Q. Lo, and D. L. Kwong, Opt. Express 16, 6425 (2008).

11. R. Takei, S. Manako, E. Omoda, M. Suzuki, M. Mori, Y. Sakakibara, and T. Kamei, Appl. Phys. Express 5, 082501 (2012).

12. R. E. I. Schropp, Thin Solid Films 451-452, 455 (2004).

13. K.-Y. Chan, D. Knipp, A. Gordijn, and H. Stiebig, J. NonCryst. Solids 354, 2505 (2008).

14. E. Jaberansary, T. M. B. Masaud, M. Nedeljkovic, M. Milosevic, G. Z. Mashanovich, and H. M. H. Chong, IEEE Photon. J. 5, 6601010 (2013). 